\title{
Metal vacancies in $\mathrm{Cd}_{1-\mathrm{x}} \mathrm{Zn}_{\mathrm{x}} \mathrm{S}$ quantum dots
}

\author{
I.M. Kupchak ${ }^{1}$, D.V. Korbutyak ${ }^{1}$, N.F. Serpak ${ }^{2}$, A. Shkrebtii ${ }^{3}$ \\ ${ }^{1}$ V. Lashkaryov Institute of Semiconductor Physics, NAS of Ukraine \\ 45, prospect Nauky, 03680 Kyiv, Ukraine, \\ ${ }^{2}$ National Pirogov Memorial Medical University, \\ 56, Pyrohova str., 21018 Vinnytsia, Ukraine \\ ${ }^{3}$ Ontario Tech University, 2000 Simcoe St. N., Oshawa, ON, L1G 0C5, Canada \\ E-mail:kupchak@isp.kiev.ua
}

\begin{abstract}
Structural and electronic characteristics of metal vacancies in nanocrystals $\mathrm{Cd}_{1-\mathrm{x}} \mathrm{Zn}_{\mathrm{x}} \mathrm{S}$ have been studied within the density functional method. The electron state density and vacancy formation energy have been calculated, and an analysis of structural relaxation has been performed. With these theoretical findings and available experimental data, we have concluded that the vacancies of cadmium are the possible centers of radiative recombination in these structures.
\end{abstract}

Keywords: cadmium sulfide, nanocrystal, photoluminescence, vacancy, density functional method.

Manuscript received 14.02.19; revised version received 03.03.20; accepted for publication 18.03.20; published online 23.03.20.

https://doi.org/10.15407/spqeo23.01.66

PACS 61.46.Hk, 68.65.Hb, 71.15.Mb, 78.55.Et

\section{Introduction}

Semiconductor quantum dots (QDs) $\mathrm{A}^{2} \mathrm{~B}^{6}$ produced using the colloidal synthesis methods usually have unimodal size distribution, which provides a narrow PL band and high quantum yield [1]. It allows using them as a lightemitting material in rigorous important technological applications, such as light sources, photoconverters, biological markers etc. [2]. The most important feature of QDs is the possibility to tune their photoluminescence by controlling the size: at sufficiently large sizes, luminescence has the exciton nature, and, therefore, the quantum-size effect takes place here. However, at small sizes, the ratio surface-to-volume is increased, which gives rise in surface luminescence and dumps the quantum-size effect: with the decrease in the currents localization, the contribution of fundamental absorption is also decreased and contribution from the localized states becomes dominant. The nature of these localized states often remains uncertained, because of the large number of possible kinds of defects in both of QD and its surrounding. Particularly, there are a series of articles [3-9], devoted to studying the PL properties and ascertaining the possible mechanism of radiative recombination in CdS QDs, where the cadmium vacancy is defined as the most probable channel of luminescence.

Another approach to control radiation is modification of the QDs composition. Introducing zinc impurities into $\mathrm{CdS} \mathrm{QD}$, one can obtain the band gap with the width $2.42 \ldots 3.91 \mathrm{eV}$, accordingly to the impurity concentration. Along with that, the density of electronic states near the valence band top increases and the crystal structure is improved [10, 11]. It allows extending the field of application for this material. Particularly, QDs $\mathrm{CdZnS}$ is a promising material for photoconverters in tandem solar cells [12]. Thus, the quantum yield of QDs CdZnS:Mn $d-d$ emission reaches more than $30 \%$ with the total quantum yield of $78 \%$, what is much better that one in well studied $\mathrm{ZnSe}$ and $\mathrm{ZnS}$ QDs, which quantum yield does not exceed 50\% [13]. Nanocrystals of such ternary compounds as $\mathrm{Cd}_{1-\mathrm{x}} \mathrm{Zn}_{\mathrm{x}} \mathrm{S}$ are studied widely in the works $[10,14,15]$. Structural studies [10,11] shows that $\mathrm{CdS}$ of cubic symmetry predominates in $\mathrm{Cd}_{1-\mathrm{x}} \mathrm{Zn}_{\mathrm{x}} \mathrm{S}$ QDs at the concentration $x=0 \ldots 1$, while this symmetry of separated $\mathrm{CdS}$ or $\mathrm{ZnS}$ phases does not appear, indicating that the ternary composition is formed. PL spectra of these samples demonstrate the broad bands, which could be related with the presence of surface defects [16, 17]. As shown in [10], defect bands are present in the whole range of zinc concentrations in $\mathrm{CdS}$ QDs, including undoped $\mathrm{CdS}$ and $\mathrm{ZnS}$, and, therefore, the possible kind of defects can be the native defects vacancies or intersite defects. The role of zinc vacancies in $\mathrm{ZnS}$ QDs in luminescence is discussed in the works [18, 19], where these defects are ascertained to be responsible for the blue radiation. This work is aimed at studying such defects as cadmium vacancy $\mathrm{V}_{\mathrm{Cd}}$, zinc vacancy $\mathrm{V}_{\mathrm{Zn}}$ in $\mathrm{Cd}_{1-\mathrm{x}} \mathrm{Zn}_{\mathrm{x}} \mathrm{S}$ QDs. 

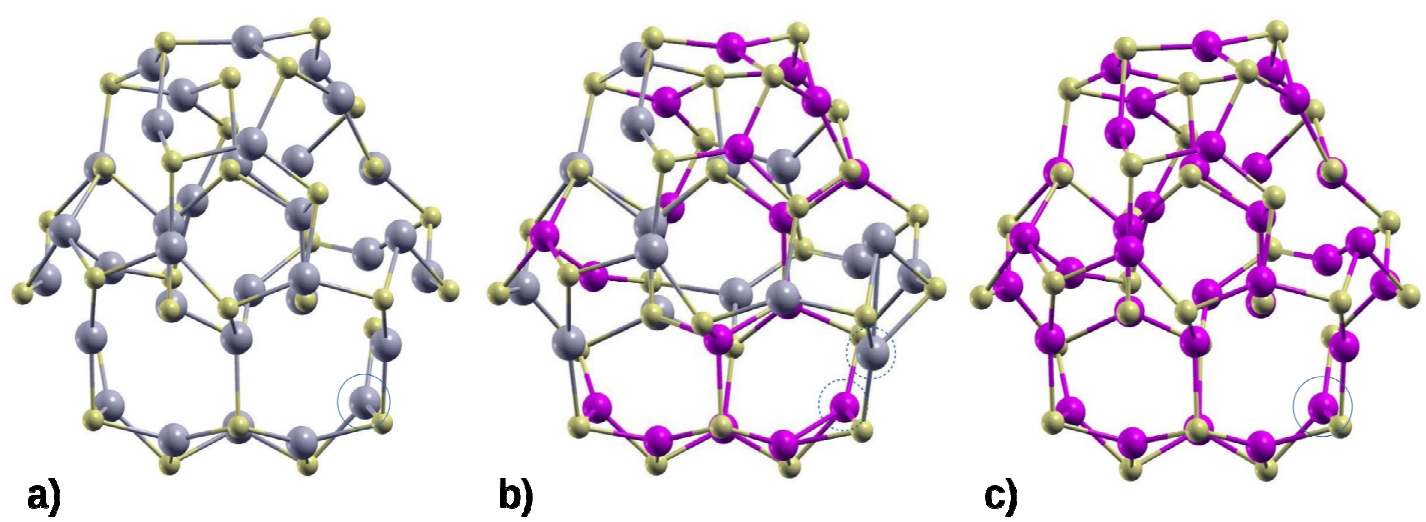

Fig. 1. Atomic structure of geometry-optimized clusters $\mathrm{CdS}, \mathrm{Cd}_{0.5} \mathrm{Zn}_{0.5} \mathrm{~S}$ and $\mathrm{ZnS}$. Yellow color denotes sulfur, gray - cadmium and purple - zinc. Dashed circles denote the atoms removed to form the vacancy. (Color online.)

\section{Method of calculation}

QD atomic structure calculation has been performed within the density functional method in generalized gradient approximation, as implemented in QuantumEspresso software package [20]. To simulate a single QD, we used atomic cluster $\mathrm{Cd}_{33} \mathrm{~S}_{33}$ in a cubic unit cell with the lattice parameter $30 \AA$. In this case, the distance between the periodic images (vacuum layer thickness) was not less than $18 \AA$, making the cluster sufficiently separated to treat it as isolated. We used the MartynaTuckerman method for correct treating the long-range interactions in such isolated systems [21]. We used the Perdew-Burke-Ernzerhof (PBE) pseudopotentials in ultra-soft form, which takes into account $4 d^{10} 5 s^{2}$ valence electrons for cadmium, $3 s^{2} 3 p^{4}$ for sulfur and $3 d^{10} 4 s^{2}$ for zinc. Integration of the Brillouin zone was performed using single $\Gamma$-point and Methfessel-Paxton smearing of $0.05 \mathrm{eV}$ [22]. We performed a set of test calculations, and all the results converged well with a 80 Ry cutoff in the wave functions and $180 \mathrm{Ry}$ in the augmented charge density, therefore, we used these parameters across the work.

\section{Results and discussions}

As it was described in [10] and discussed above, PL spectra of $\mathrm{Cd}_{1-\mathrm{x}} \mathrm{Zn}_{\mathrm{x}} \mathrm{S}$ QDs show the bands, which are obviously related with the presence of surface defects. Particularly, the most probable kind of defects in $\mathrm{CdS}$ QDs, responsible for the luminescence, is the cadmium vacancy [9]. Taking it into account, we study here electronic and atomic structure of CdS, $\mathrm{ZnS}$ and $\mathrm{Cd}_{1-\mathrm{x}} \mathrm{Zn}_{\mathrm{x}} \mathrm{S}$ QDs, containing metal vacancies $\mathrm{V}_{\mathrm{Cd}}, \mathrm{V}_{\mathrm{Zn}}$. As a model, we cut approximately a spherical 66-atoms cluster $\mathrm{Cd}_{33} \mathrm{~S}_{33}$ from bulk hexagonal $\mathrm{CdS}$, with the center located in the middle of Cd-S bond. This system is stoichiometric and consists of a magic number of atoms, and, therefore, has a minimal number of dangling bonds at the surface. To model $\mathrm{ZnS}$, we used the same cluster but with zinc in the places of cadmium. In its turn, $\mathrm{Cd}_{1-\mathrm{x}} \mathrm{Zn}_{\mathrm{x}} \mathrm{S}$ QD we simulate by selecting the cluster $\mathrm{Cd}_{16} \mathrm{Zn}_{17} \mathrm{~S}_{33}$, where sort of metal atoms was distributed in a random order. This cluster preserves the condition of minimal number of surface broken bonds and has a component composition close to that of $\mathrm{Cd}_{0.5} \mathrm{Zn}_{0.5} \mathrm{~S}$.
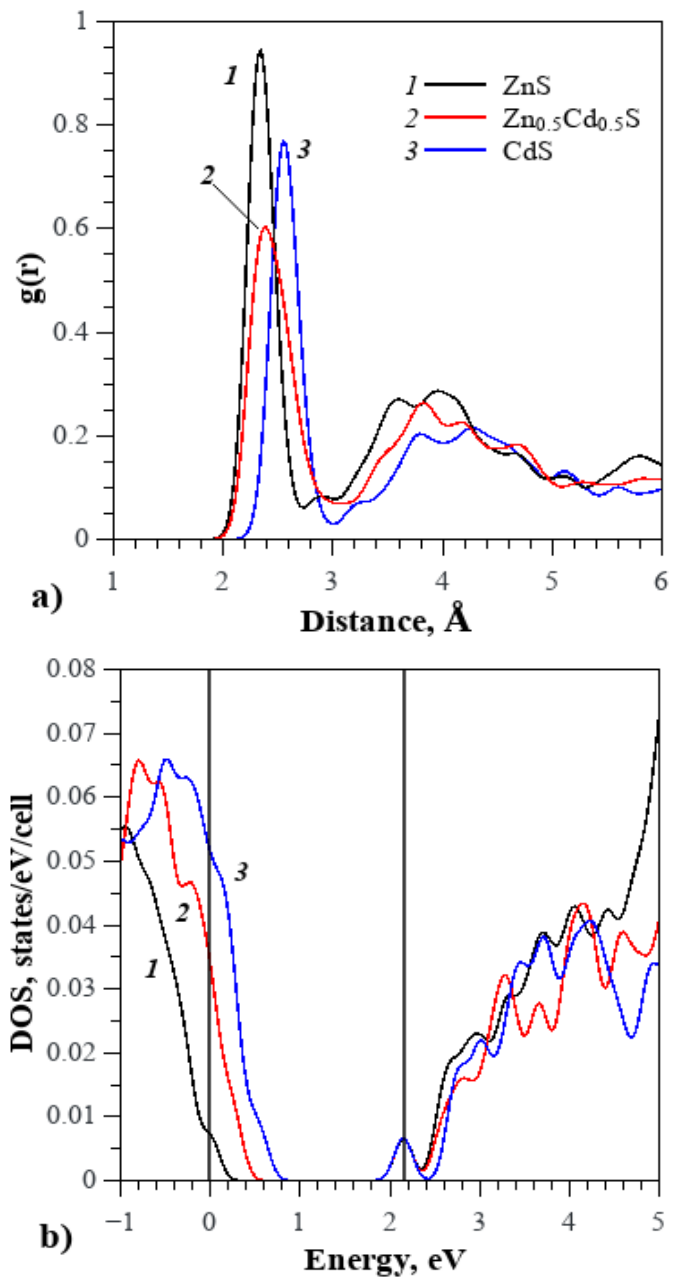

Fig. 2. Radial distribution function (a) and density of electron states (b) calculated for the clusters $\mathrm{CdS}, \mathrm{ZnS}$ and $\mathrm{Cd}_{0.5} \mathrm{Zn}_{0.5} \mathrm{~S}$.

All the systems were relaxed until the HellmannFeynman forces became less than $10^{-4}$ a.u., after that the energy spectra calculations were performed. In Fig. 1, we show the optimized atomic structure of the systems $\mathrm{Cd}_{0.5} \mathrm{Zn}_{0.5} \mathrm{~S}$, CdS and $\mathrm{ZnS}$. One can see that all these systems have a similar geometrical structure and are close to cubic symmetry, which, however, cannot be ascertained exactly, because of a small number of atoms. 

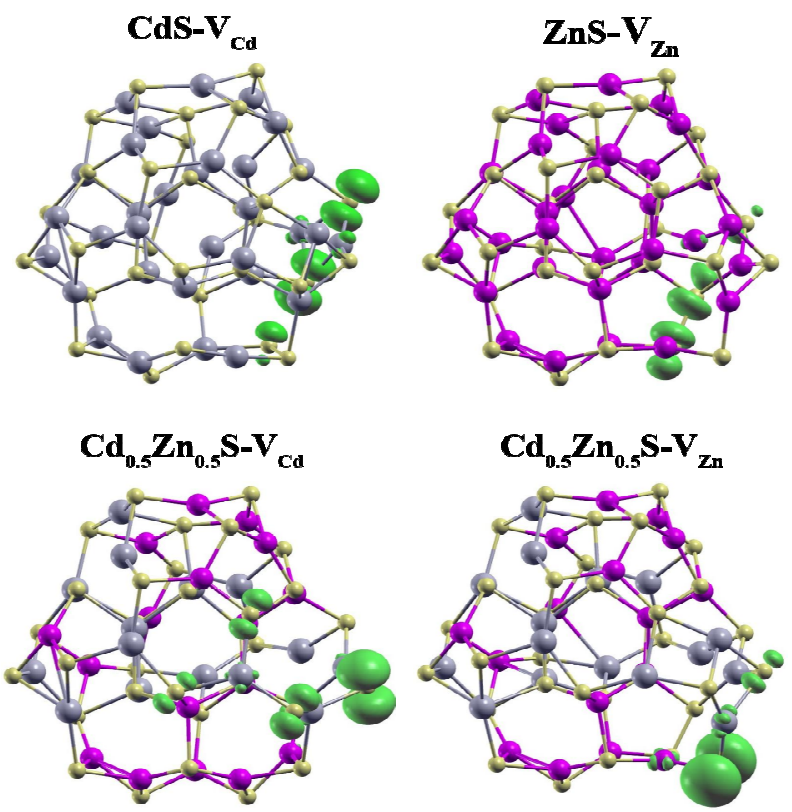

Fig. 3. Atomic structure of optimized clusters containing the metal vacancies $\mathrm{V}_{\mathrm{Cd}}$ and $\mathrm{V}_{\mathrm{Zn}}$. Green color indicates the electron charge density distribution as calculated using HOMO only. (Color online.)

The calculated radial distribution function $g(r)$ obtained using Gaussian convolution with the half-width close to 0.1 a.o. for all the systems is depicted in Fig. 2a. The first peak maximum, corresponding to the first coordination sphere radius, is located at $2.56 \AA$ for $\mathrm{CdS}, 2.40 \AA$ for $\mathrm{Cd}_{0.5} \mathrm{Zn}_{0.5} \mathrm{~S}$ and $2.35 \AA$ for $\mathrm{ZnS}$. As expected, $\mathrm{ZnS}$ has smaller lattice parameter than $\mathrm{CdS}$, and the lattice parameter of $\mathrm{Cd}_{0.5} \mathrm{Zn}_{0.5} \mathrm{~S}$ is found to be an average of these values. The calculated density of states have a similar behavior, as can be seen from Fig. 2 b: vertical lines denote the calculated band gap (HOMO-LUMO) of $\mathrm{ZnS} \mathrm{QD}$, therefore, with decreasing the zinc concentration, the band gap is also decreasing from 2.15 to $1.59 \mathrm{eV}$. In all the cases, there are no any peaks within the band gap, which indicates the absence of surface (defect) states. It is worth noting that all the densities of states were obtained using Gaussian convolution with the half-width close to $0.1 \mathrm{eV}$, to avoid the redundant details, so the band gap edges became somewhat smooth.

We simulated the metal vacancy by removing a single cadmium or zinc atom from defect-free system, circled by dashed lines in Fig. 1, with following geometry optimization. Optimized structure together with electronic charge distribution obtained with the wavefunction of HOMO state are shown in Fig. 3. One can see that, in general, after geometry optimization, all the clusters still keep some crystal structure, and the largest changes occur in the vacancy region. It is obvious from the calculated charge density distribution that HOMO level is mostly formed with the states of the nearest to the vacancy sulfur atoms, whereas metal atoms practically do not contribute into this state. Therefore, in all the systems under study the HOMO level could be considered as a defect (vacancy) level. To verify this assumption, we calculated the density of electron states for $\mathrm{CdS}$, $\mathrm{Cd}_{0.5} \mathrm{Zn}_{0.5} \mathrm{~S}$ and $\mathrm{ZnS}$ clusters, as shown in Fig. 4: black lines - defect-free cluster (bare), red (blue) lines clusters containing corresponding metal vacancy. As seen, in all the clusters the metal vacancy leads to additional energy level appearance in the band gap. Moreover, in a case of CdS, this level is located near the top of valence band, whereas in $\mathrm{ZnS}$ it is separated to the region of $0.9 \mathrm{eV}$. Similar situation is with the solution $\mathrm{Cd}_{0.5} \mathrm{Zn}_{0.5} \mathrm{~S}$ : the cadmium vacancy forms the level close to valence band top of defect-free cluster, while the zinc vacancy - inside the band gap at the energy $0.8 \mathrm{eV}$.
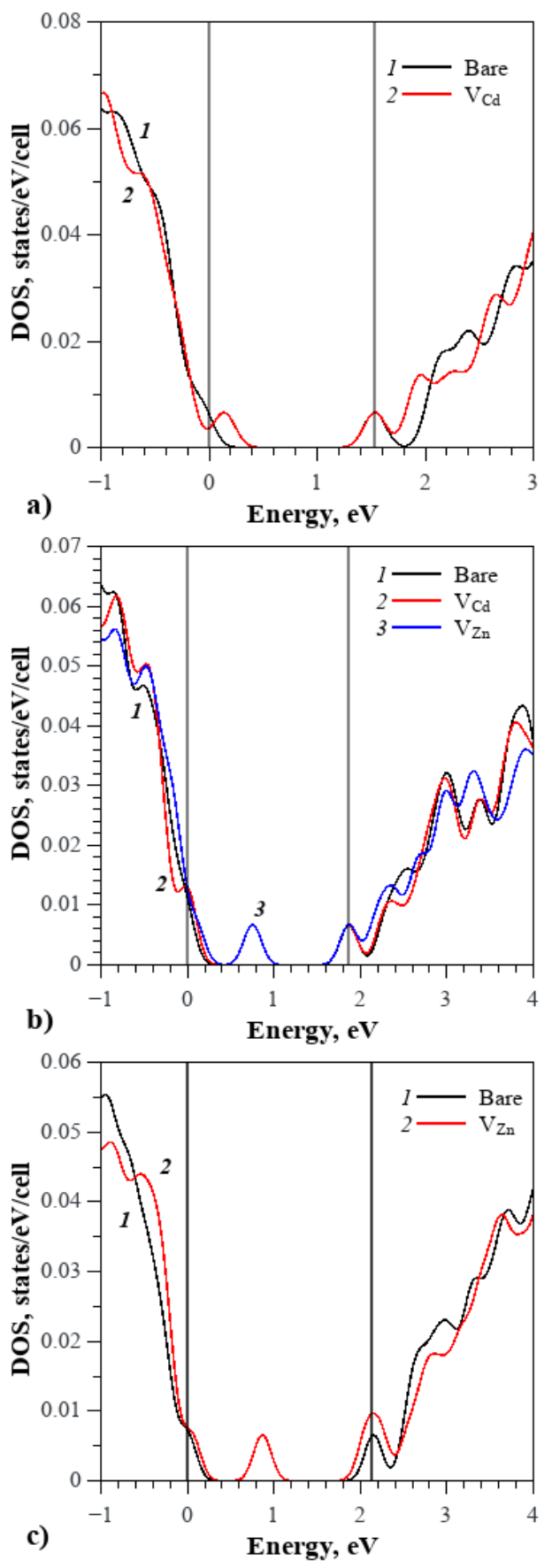

Fig. 4. Density of electron states for the clusters CdS (a), $\mathrm{Cd}_{0.5} \mathrm{Zn}_{0.5} \mathrm{~S}$ (b) and $\mathrm{ZnS}$ (c) containing metal vacancies. 
We calculated the neutral vacancy formation energy $E_{f}(\mathrm{X})$ by using the formula $E_{f}(\mathrm{X})=E_{\text {tot }}-\left(E_{\text {tot }}(\mathrm{X})+\mu(\mathrm{X})\right)$ [23], where $E_{\text {tot }}$ is the calculated total energy of defectfree cluster, $E_{\text {tot }}(\mathrm{X})$ - calculated total energy of a cluster with a vacancy of a metal $X-$ cadmium or zinc, and $\mu(X)$ - chemical potential of the atom X. Since technology of $\mathrm{Cd}_{1-\mathrm{x}} \mathrm{Zn}_{\mathrm{x}} \mathrm{S}$ QDs growth assumes an excess of sulfur in a colloidal solution [10], then in these sulfur-rich conditions the precipitate of crystalline sulfur can be formed, and, therefore, we can approximate the chemical potential of sulfur atoms in the cluster by the corresponding value inherent to the bulk. Moreover, the sum of chemical potentials of metal $X$ and chalcogen $S$ must be equal to the chemical potential of molecular unit: $\mu(\mathrm{X})+\mu(\mathrm{S})=\mu(\mathrm{XS})$. Under these conditions, we can determine the chemical potentials of cadmium and zinc in corresponding chalcogenides, however, these conditions are not sufficient to determine the metal chemical potential in the ternary compound. Therefore, we have to assume here that the chemical potential of cadmium and zinc in the ternary compound are close to those in binary compounds $\mathrm{CdS}$ and $\mathrm{ZnS}$, respectively. To determine the chemical potential of sulfur, we calculated the total energy of 32-atoms unit cell of bulk sulfur $\alpha$-S(16). To calculate cadmium and zinc chemical potentials, we calculated the total energy of hexagonal $\mathrm{CdS}$ and $\mathrm{ZnS}$ unit cells, respectively. All the parameters were the same as in QDs calculations, apart the $k$-points grid: for sulfur, we employ $4 \times 4 \times 4$, and for $\mathrm{CdS}$ and $\mathrm{ZnS}$ $-12 \times 12 \times 12 \Gamma$-centered grids. As a result, for the binary compounds, the formation energy of a neutral metal vacancy are obtained with the close values: $E_{f}(\mathrm{Cd})=0.68 \mathrm{eV}$ and $E_{f}(\mathrm{Zn})=0.70 \mathrm{eV}$. In the ternary compound $\mathrm{Cd}_{0.5} \mathrm{Zn}_{0.5} \mathrm{~S}$, the situation is different: the cadmium vacancy formation energy appeared to be $E_{f}(\mathrm{Cd})=1.23 \mathrm{eV}$, which exceeds significantly the formation energy $E_{f}(\mathrm{Zn})=0.65 \mathrm{eV}$ of zinc vacancy. The changes in cluster atomic structure during the process of cadmium vacancy formation are also significant: the largest atomic displacement is $2.86 \AA$, and its total RMS value is $0.40 \AA$, whereas in the case of zinc vacancy these values are 1.50 and $0.37 \AA$, respectively. Such a large value of cadmium vacancy formation energy and atomic displacement are the consequence of a more strong cluster relaxation: the nearest to vacancy cadmium atom migrates and occupies the empty site, creating a new vacancy with the following moderate changes in atomic structure of its nearest environment. In the case of zinc vacancy, no atomic migration occurs, and all the changes in atomic structure are related with the nearest atoms. In undoped $\mathrm{CdS}$ structures, cadmium vacancy formation leads to the largest atomic displacement of $1.65 \AA$ and total RMS - $0.49 \AA$. For $\mathrm{ZnS}$ cluster, these values are 1.86 and $0.60 \AA$, respectively. Therefore, for all of clusters under study atomic displacements during the vacancy formation got the close values, apart the cadmium vacancy in $\mathrm{Cd}_{0.5} \mathrm{Zn}_{0.5} \mathrm{~S}$, where the relaxation process is much stronger. However, even with this strong relaxation, the high value of formation energy makes this defect less probable as compared to other vacancies, although, as one can see in Figs $4 a$ and $4 b$, the cadmium vacancy forms the local states near the valence band top and together with the zinc vacancy could serve as a channel of radiative recombination. On the other hand, PL spectra of CdS and CdS:Zn [10, 11, 24] shows bands within the range $2.1 \ldots 2.3 \mathrm{eV}$, which is in favor of the cadmium vacancy as a possible channel of radiative recombination in $\mathrm{Cd}_{0.5} \mathrm{Zn}_{0.5} \mathrm{~S}$ QDs.

\section{Conclusions}

In this work, we studied $a b$ initio atomic and electronic structures of $\mathrm{CdS}, \mathrm{ZnS}$ and $\mathrm{Cd}_{0.5} \mathrm{Zn}_{0.5} \mathrm{~S}$ QDs by modeling the atomic clusters $\mathrm{Cd}_{33} \mathrm{~S}_{33}, \mathrm{Zn}_{33} \mathrm{~S}_{33}$, and $\mathrm{Cd}_{16} \mathrm{Zn}_{17} \mathrm{~S}_{33}$. Metal vacancy formation energies and the magnitude of the following structure relaxation have been calculated in these structures. It has been found that neutral cadmium vacancy in $\mathrm{CdS}$ and $\mathrm{Cd}_{0.5} \mathrm{Zn}_{0.5} \mathrm{~S}$ forms the local states near the valence band top, whereas the zinc vacancy produces the local state at $0.9 \mathrm{eV}$ in the energy gap. Taking into account that experimental PL spectra of CdS and CdS:Zn QDs show the bands within $2.1 \ldots 2.3 \mathrm{eV}$ region, we can say that the cadmium vacancies are the possible channels of radiative recombination in $\mathrm{Cd}_{1-\mathrm{x}} \mathrm{Zn}_{\mathrm{x}} \mathrm{S}$ QDs.

\section{Acknowledgments}

We thank the Shared Hierarchical Academic Research Computing Network (Sharcnet) of Ontario, Canada, for the provided CPU time.

\section{References}

1. Korbutyak D.V., Kovalenko O.V., Budzulyak S.I., Kalytchuk S.M., Kupchak I.M. Light-emitting properties of $\mathrm{A}_{2} \mathrm{~B}_{6}$ semiconductor quantum dots. Ukr. J. Phys. Reviews. 2012. 7, No 1. P. 48-94.

2. Klimov V.I. Nanocrystal Quantum Dots, 2nd ed. CRC Press, Boca Raton, 2010.

3. Rudko G.Y., Vorona I.P., Fediv V.I. et al. Luminescent and optically detected magnetic resonance studies of CdS/PVA nanocomposite. Nanoscale Res. Lett. 2017. 12, No 1. P. 130. https://doi.org/10.1186/s11671-017-1892-4.

4. Skobeeva V.M., Sviridova O.I., Tyurin A.V., Smyntyna V.A., Struts D.A. Optical properties of cadmium sulfide nanocrystals obtained by the solgel method in gelatin. J. Appl. Spectroscopy. 2008. 75, No 4. P. 576-582. https://doi.org/10.1007/s10812-008-9074-x.

5. Mandal P., Talwar S.S., Major S.S., and Srinivasa $\mathrm{R}$. Orange-red luminescence from $\mathrm{Cu}$ doped $\mathrm{CdS}$ nanophosphor prepared using mixed LangmuirBlodgett multilayers. J. Chem. Phys. 2008. 128. P. 114703. https://doi.org/10.1063/1.2888930.

6. Lee H., Yang H., and Holloway P.H. Functionalized CdS nanospheres and nanorods. Phys. B: Condens. Matter. 2009. 404, No 22. P. 4364-4369. https://doi.org/10.1016/j.physb.2009.09.020.

7. Yuan S.Q., Ji P.F., Li Y., Song Y.L., and Zhou F.Q. Unusual blueshifting of optical band gap of CdS nanocrystals through a chemical bath deposition method. Adv. Optoelectron. 2015. 2015. Article ID 317108 (5 p.). https://doi.org/10.1155/2015/317108. 
8. Smyntyna V., Semenenko B., Skobyeyeva V., Malushyn M. Effect of surface on the luminescence properties of $\mathrm{CdS}$ nanocrystals. Electron. Inform. Technologies. 2012. No 2. P. 45-50 (in Ukrainian).

9. Korbutyak D.V., Kapush O.A., Serpak N.F., Kupchak I.M. Electronic properties of surface vacancies in $\mathrm{CdS}$ nanocrystals. Physics and Chemistry of Solid State. 2018. 19, No 1. P. 34-39. https://doi.org/10.15330/pcss.19.1.34-39.

10. Korbutyak D.V., Kladko V.P., Safryuk N.V. et al. Synthesis, luminescent and structural properties of the $\mathrm{Cd}_{1-\mathrm{x}} \mathrm{Cu}_{\mathrm{x}} \mathrm{S}$ and $\mathrm{Cd}_{1-\mathrm{x}} \mathrm{Zn}_{\mathrm{x}} \mathrm{S}$ nanocrystals. J. Nanoand Electron. Phys. 2017. 9, No 5. P. 05024. https://doi.org/10.21272/jnep.9(5).05024.

11. Muruganandam S., Anbalagan G., and Murugadoss G. Synthesis and structural, optical and thermal properties of $\mathrm{CdS}: \mathrm{Zn}^{2+}$ nanoparticles. Appl. Nanosci. 2014. 4. P. 1013-1019. https://doi.org/10.1007/s13204-013-0284-z.

12. Wu K., Li H., and Klimov V.I. Tandem luminescent solar concentrators based on engineered quantum dots. Nat. Photonics. 2018. 12, No 2. P. 105-110. https://doi.org/10.1038/s41566-017-0070-7.

13. Beaulac R., Archer P.I., and Gamelin D.R. Luminescence in colloidal $\mathrm{Mn}^{2+}$-doped semiconductor nanocrystals. J. Solid State Chem. 2008. 181, No 7. P. 1582-1589.

https://doi.org/10.1016/j.jssc.2008.05.001.

14. Milekhin A.G., Yeryukov N.A., Sveshnikova L.L. et al. $\mathrm{CdZnS}$ quantum dots formed by the Langmuir-Blodgett technique. J. Vac. Sci. Technol. B. 2013. 31, No 4. Article number 04D109. https://doi.org/10.1116/1.4810782.

15. Park S.Y., Kim H.-S., Yoo J. et al. Long-term stability of $\mathrm{CdSe} / \mathrm{CdZnS}$ quantum dot encapsulated in a multi-lamellar microcapsule. Nanotechnology. 2015. 26, No 27. P. 275602. https://doi.org/10.1088/0957-4484/26/27/275602.

16. Saunders A.E., Popov I., and Banin U. Synthesis of hybrid CdS-Au colloidal nanostructures. J. Phys. Chem. B. 2006. 110. P. 25421-25429. https://doi.org/10.1021/jp065594s.

17. Ping Yang, Meng Kai Lü, Chun Feng Song et al. Luminescence of $\mathrm{Cu}^{2+}$ and $\mathrm{In}^{3+}$ co-activated $\mathrm{ZnS}$ nanoparticles. Opt. Mater. 2002. 20, No 2. P. 141. https://doi.org/10.1016/S0925-3467(02)00060-5.

18. Denzler D., Olschewski M., and Sattler K. Luminescence studies of localized gap states in colloidal ZnS nanocrystals. J. Appl. Phys. 1998. 84. P. 2841. https://doi.org/10.1063/1.368425.

19. Li H., Shih W.Y., and Shih W.H. Stable aqueous $\mathrm{ZnS}$ quantum dots obtained using (3-mercaptopropyl) trimethoxysilane as a capping molecule. Nanotechnology. 2007. 18. P. 495605. https://doi.org/10.1088/0957-4484/18/49/495605.

20. Giannozzi P., Baroni S., Bonini N. et al. QUANTUM ESPRESSO: a modular and open-source software project for quantum simulations of materials. J. Phys.: Cond. Matter. 2009. 21, No 39. P. 395502. https://doi.org/10.1088/0953-8984/21/39/395502.

21. Martyna G.J. and Tuckerman M.E. A reciprocal space based method for treating long range interac- tions in ab initio and force-field-based calculations in clusters. J. Chem. Phys. 1999. 110, No 6. P. 2810-2821. https://doi.org/10.1063/1.477923.

22. Methfessel M. and Paxton A.T. High-precision sampling for Brillouin-zone integration in metals Phys. Rev. B. 1989. 40. P. 3616. https://doi.org/10.1103/PhysRevB.40.3616.

23. Van de Walle C.G., Neugebauer J. First-principles calculations for defects and impurities: Applications to III-nitrides. J. Appl. Phys. 2004. 95, No 8. P. 3851-3879. https://doi.org/10.1063/1.1682673.

24. Yong Li, Shu Qing Yuan, Xin Jian Li. White light emission from $\mathrm{CdS} / \mathrm{Si}$ nanoheterostructure array. Mater. Lett. 2014. 136. P. 67-70.

https://doi.org/10.1016/ j.matlet.2014.08.001.

\section{Authors and CV}

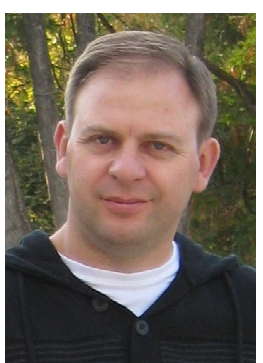

Kupchak I.M. Ph.D in Physics and Mathematics, Senior researcher at the V. Lashkaryov Institute of Semiconductor Physics. The area of his scientific interests includes computational physics applied to the study of electronic, structural, magnetic and optical properties of quantum-sized semiconducting structures, scientific code development and high-performance calculations.

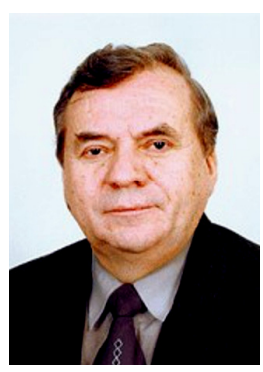

Korbutyak D.V. Professor, Doctor of Sciences in Physics and Mathematics, Head of Department of surface physics and semiconductor nanophotonics at the V. Lashkaryov Institute of Semiconductor Physics. The area of his scientific interests includes solid state physics, optical diagnostics, $\mathrm{A}^{2} \mathrm{~B}^{6}$ semiconductor nanocrystals.

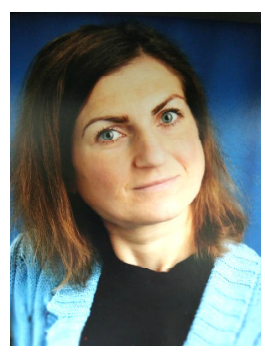

Serpak N.F. Ph.D in Physics and Mathematics. She is working as assistant professor at the National Pirogov Memorial Medical University, Department of biophysics, informatics and medical equipment. The area of her scientific interests includes semiconductor nanomaterials, particularly electronic, optical and structural properties of quantum dots.

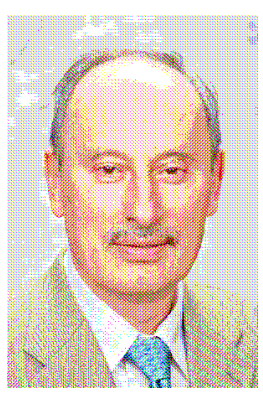

Shkrebtii A.I. Professor, Ph.D. in Physics and Mathematics, Professor at the University of Ontario, Institute of Technology. The area of scientific interests of Prof. Shkrebtii includes solid state physics, semiconductors and their surfaces as well as nanomaterials, nonlinear optical phenomena, electronic, structural and dynamical properties of novel materials. 